\section{Cat's Toes}

Aт the village of Cookham-Dean, near Maidenhead, there is a race of cats having more than their normal complement of toes. They generally have six toes on the fore feet, and the usual number on the hind feet; but I saw two individuals which had six toes on each foot, and others which had seven toes on the fore feet, and either five or six on the hind feet. The stock, as far as I can learn from the not over-bright natives, appears to have originated about seven or eight years ago in the person of a "Tom" having six toes on each of its feet. I should think there are now a score or more living in the village.

Harpenden, Sept. Ig

R. LYDEKIKER

\section{NEW INSTRUMENT FOR THE PRODUCTION} OF OZONE

TN the American Fournal of Science and Arts for July I872, Prof. A. W. Wright, of Yale College, describes a simple apparatus for the production of ozone with electricity of high tension, and intended for use with the Holtz electrical machine. "The apparatus consists of a straight glass tube about 20 centimetres long and having an internal diameter of 2.5 centimetres, the two ends being stopped with corks covered on the inner side with a thin coating of cement to protect them from the action of the ozone. Through the axis of each cork is inserted a glass tube of about 5 millimetres calibre, and 7 centimetres in length, having a branch tube inserted perpendicularly at the middle, and long enough to permit a rubber tube to be slipped upon it. The outer ends of the tubes themselves are closely stopped with corks, through which are passed straight thick copper wires carrying suitable terminals at their inner ends, and bent into a ring at the others. They are fitted so as to make tight joints, but to allow of motion in order to vary the distance between their inner ends. One of these wires carries a small ball, the other terminates in a disc with rounded edge, set perpendicularly to the axis of the tube, and so large as to leave an annular space of some two or three millimetres breadth around it. The gas is admitted through one of the branch tubes, and escapes from the other after having passed through the whole length of the tube.

"In using the apparatus the wires must be connected with the poles of the machine in such a manner that the disc becomes the negative terminal, as this arrangement gives the greatest degree of expansion and diffusiveness to the current. On turning the machine, and adjusting the ball and disc to a proper distance, a nebulous aigrette surrounds the latter, quite filling the interval between it and the wall of the tube, while the part of the tube between the disc and ball is crowded with innumerable hazy streams converging upon the positive pole, or simply causing the latter to be covered with a faint glow. A current of air or oxygen sent into the tube must pass through this, and ozone is very rapidly produced, and in great quantity. The condensers are of course not used with the machine, when this apparatus is employed.

"The great quantity of the ozone, as well as the ease and rapidity with which it is produced, render the apparatus especially serviceable for use in the lecture-room."

\section{THE FRENCHI ASSOCTATION FOR THE ADVANCEMENT OF SCIENCE}

I F a good start in life is as serviceable for a society as for an individual, the French Association for the Advancement of Science must be considered as highly fortunate. There has already appeared in NATURE a short account of its first meeting at Bordeaux, and of the papers read there; but the impressions of one of its invited guests may not be altogether without value or interest.

Confessedly the French was framed on the model of the British Association, and doubtless there was wisdom in that; but our friends across the Channel showed their wisdom also in making no servile copy, but endeavouring to modify our plans, so as to suit their national character or special requirements. The reception-room, the card of admission with a map of the town on the back, the various sections in the morning, the discourses in the evening, the municipal hospitality, all reminded us strongly of our own meetings; yet there were some differences that could not fail to strike an English visitor.

In the first place, it was not so popular an assembly. This arose partly from its constitution. There are two kinds of membership ; there are the foundation members, who have qualified by taking one or more shares of 500 francs each, and subscribers who pay 20 francs for the meeting or a life composition. By enrolling these members a large society was created with a large capital before ever the first place of meeting was named. And very quickly was this accomplished; for it was only about Midsummer of last year that $M$. Friedel talked with $M$. Wurtz as to the best means of extending knowledge through the departments of France, and it was only last Midwinter that the project was nearly shipwrecked by the sudden and lamentable death of M. Combes, in whose rooms the first meeting had been held, and who had been named the provisional president ; yet by the aid of largehearted friends, such as M. D'Eichthal and M. Menier ("Chocolat-Menier"), the promoters of the movement were able to announce in April a sufficient capital to start with, and before the meeting at Bordeaux the Association numbered 700 members, and possessed 140,000fr.

No provision had been made for ladies' tickets, so when the meeting opened there was a sombre uniformity of black coats. But the English visitors brought ladies with them; there was a learned lady, who was believed to be writing for the press, and another, Madame Hureau de Villeneuve, followed her husband's paper on the Steam-engine by reading one of her own on the Flight of Birds. Encouraged by these, several other ladies made their appearance, and brightened the later meetings.

The accommodation afforded by Bordeaux was singularly good. The brilliant concert-room of the great theatre (which is historically interesting from the National Assembly having been convened in it during the German war) was given as the reception-room ; and all the meetings were held in the Ecole Professionnelle, a large building just erected in a very substantial manner by the Philomathic Society, with funds bequeathed for the purpose. This new edifice contains a large lecture-room, which served well for the general meetings, and no end of good class-rooms, which accommodated the eleven sections into which the Association was divided. It is intended for the instruction of the working classes of the neighbourhood in the natural sciences, modern languages, drawing, \&c., and so the sittings of the large scientific body were a good inauguration of its future work.

The great subdivision of the sections naturally gave rise to but small audiences in each. As far as I could judge, the chemists and the anthropologists were in greatest force; few naturalists or geologists of eminence were present. The sectional proceedings had more the character of a sitting of one of our learned societies than of a morning gathering at the British ${ }^{\ddagger}$ Association ; but besides a couple of hours thus devoted to more abstruse points of science, there was an afternoon sitting at which subjects of more general interest were brought forward. This came intermediate in character, as in time, between the morning sections and the evening discourses ; and it is a fair matter for consideration whether it might not be advantageously copied by us. 
The papers seemed on the whole superior to those brought forward at our Association, at least there were fewer communications of trivial importance, or old subjects warmed up afresh. Our neighbours, however, find discussion a difficult thing; it is apt to degenerate at once into a conversation between two heated opponents. There was evident also a want of order, punctuality, and respect for authority ; previous arrangements were altered, or the decisions of the chair set aside, in the coolest manner. A want of proper organisation arose from the fact that $M$. Claude Bernard, the president, never made his appearance on account of ill-health; but M. Cornu, the general secretary, was a host in himself; and as $\mathbf{M}$. de Quatrefages has accepted the presidentship of the next meeting at Lyons, and Prof. Wurtz, whose energy and good nature were unfailing at Bordeaux, is to occupy the post of honour the year following, we may hope that the young Association will quickly get over the diseases of infancy.

Festivities were not wanting. Chief among these was a grand reception by the Mayor at the Hôtel de Ville, but I may specially mention a déjeuner given by the French chemists to their brethren from England and Belgium, Holland and Spain. Some of us also will never forget the private hospitality we met with.

But the excursions were the great feature of the meeting, and in them the copy certainly surpassed the original. They played a most important part in the proceedings; Saturday and Tuesday were wholly devoted to them; and they took place on Sunday, on Monday afternoon, and through the three days after the close of the sittings.

There was the expedition to Árcachon, where the savans not only strolled about the pretty watering-place, but studied natural history at an aquarium which, unlike that at Brighton, was a very unpretending building, but well stocked with interesting marine animals, and paid an especial visit to the oyster-beds that have been formed on sandbanks in the middle of the land-locked sea in front of the town. Here we traced the growth of the favourite mollusc from the spat on tiles, till it was large and plump, and we had explained to us the difficulties of its cultivation, and the ravages committed by a murex called Carmaillot (I am spelling at random) and by the hermit crabs. There was an antiquarian expedition to Perigueux and Les Eyzies, where, on each side of the valley, the limestone cliffs are fissured with caverns, in which men lived, and worked in flint and bone, at that remote period when reindeer and mammoths roamed over the soil of France. There was an expedition to see the new "docks" and huge engineering works of the Garonne, which $\mathbf{M}$. Joly carefully explained; and there was a larger excursion by boat and rail down the Gironde to the open sea, where geologists had an opportunity of inspecting the cliffs of chalk and flint, and then the Tertiary strata, beside discussing the subsidence of the Gascon shore, and the shifting of the sandhills, and seeing how they are now prevented from swallowing up villages and churches as they did of old.

But the great excursion was the final one, which extended over three days, and was unique in my experience. Twenty members of the Association were officially deputed to report mainly on the industrial establishments of the Landes and Lower Pyrenees; and any other members were welcome to join the party. Thus was secured a good nucleus of really scientific men, while the expedition had a serious purpose, and it was evidently to the advantage of the establishments visited that we should be well received. The Landes, as is generally known, is a large tract of country which, until lately, was a marsh of sand scarcely capable even of affording pasture; but now it is reclaimed, and the centre of thriving industries. Forests of pine (Pinus maritima) have been planted for hundreds of miles, and the trees are regularly scored for turpentine ; maize and other crops are grown; and the undergrowth of heather supplies food for myriads of bees. At Labouheyre we inspected the means employed for separating the rosin from the turpentine, and the machinery for impregnating the pine wood with sulphate of copper, so as to fit it for railway sleepers and telegraph posts; and though the thermometer was at $32^{\circ} \mathrm{C}$. (say $90^{\circ} \mathrm{F}$.) in the shade, and anything you like to imagine in the sun, we also went carefully over some blast furnaces that are used principally for reducing by charcoal the Spanish iron ores which, being free from sulphur and phosphorus, yield an excellent metal.

Here the party was sumptuously entertained by M. Alexandre Leon ; and from this stage special trains or special carriages were placed freely at our disposal by the Compagnie du Midi. The next place visited was a primary school at Morcenx, for the gratuitous instruction of the children of their employés, which had been carried on by M. Surell the former, and M. Simon the present director of the Railway Company. We found the boys at military drill; we took part in the distribution of prizes, the Association itself giving a reward to the best boy and girl ; and as scientific men, we were particularly interested in the good provision for "object lessons," the chemical and galvanic apparatus, and the care with which the children were taught the rudiments of physical and physiological science. Rejoicing at this proof that the reclamation of the Landes was not confined to the soil, we pursued our way to Dax, and spent Friday night at the Thermal Baths, where we enjoyed the hospitality of Drs. Larauza and Delmas, the physicians of the establishment. The springs of nearly boiling water that gush from many parts of the contorted strata under the town were duly examined, and so were the deposits of rock-salt that were accidentally discovered a year or two ago, and which promise to prove an important source of wealth.

From these hot springs we travelled southwards across the Spanish frontier to Irun, and then a good walk through beautiful scenery took us among the granite mountains to the mines of Bidassoa. Here we saw how large faults in the primæval rock are filled with crystallised carbonate of iron, and how the rich ore is won.

Returning into France, where, through the kindness of M. D'Eichtal, a dinner was awaiting us, the expedition found its way back to Bayonne ; and, doubtless, on the morrow some of the party visited the pre-historic camp and the ancient abodes of the Troglodytes, according to the programme; but the chemists generally preferred a quiet day at Biarritz.

\section{J. H. GLADSTONE}

\section{THE SPIRIT OF SCIENTIFIC CONTROVERSY}

$A \mathrm{~S}$ if in atonement for a prolonged neglect, the study of the organisation of fossil plants is now receiving wide-spread attention. The task first undertaken by Henry Withan has now been shared by many observers. The result is that we already possess a much more complete acquaintance with the ancient vegetation of the globe than we did even a few years ago. But whilst this is undoubtedly true, it is equally so that wide differences of opinion on important points still exist amongst those who have taken a leading part in this investigation. Thus, M. Brongniart and Dr. Dawson believe that the Sigillariæ were Gymnospermous Exogens; whilst Mr. Carruthers and myself are convinced that they were Lepidodendroid Cryptogams. In common with Prof. Schimper and Mr. Carruthers, I regard the whole of the Calamites as Cryptogamic plants, having Equisetaceous affinities; whilst M. Brongniart, M. Grand-Eury, and, perhaps partially, Dr. Dawson, deem some of them to be Equisetaceans, and others Gymnospermous Exogens. Mr. Carruthers and Mr. Binney regard the fruits known 